\title{
Contributions and Implications of the Tehran Lipid and Glucose Study
}

\author{
Fereidoun Azizi ${ }^{1}$, Miralireza Takyar ${ }^{1}$ and Azita Zadeh-Vakili ${ }^{2,{ }^{*}}$ \\ ${ }^{1}$ Endocrine Research Center, Research Institute for Endocrine Sciences, Shahid Beheshti University of Medical Sciences, Tehran, Iran \\ ${ }^{2}$ Cellular and Molecular Endocrine Research Center, Research Institute for Endocrine Sciences, Shahid Beheshti University of Medical Sciences, Tehran, Iran \\ "Corresponding author: Cellular and Molecular Endocrine Research Center, Research Institute for Endocrine Sciences, Shahid Beheshti University of Medical Sciences, Tehran, \\ Iran. Email: azitavakili@gmail.com
}

Received 2018 September 01; Revised 2018 October 02; Accepted 2018 October 06.

\begin{abstract}
Tehran Lipid and Glucose Study (TLGS), an epidemiological study of non-communicable disease with 20 years follow up in a developing country in nutrition transition is a unique study in 15000 family based individuals, 3 - 75 years of age in a part of large city of Tehran. The success rate of recruitment for 20 years, intervention for lifestyle change, and thyroid, reproduction and cardiometabolic genetic studies derived from TLGS have paved suitable path towards precision medicine. In this review, baseline findings and changes of risk factors for the development of NCD including body weight, nutrition, physical activity, blood pressure, tobacco smoking, serum glucose and serum lipids as well as metabolic syndrome, chronic kidney disease, quality of life and biochemical findings in TLGS cohort have been summarized. The results of community based intervention for lifestyle change caused decreases in the prevalence of metabolic syndrome and the incidence of diabetes. It is concluded that TLGS has served as a model for other cohort studies in Iran and the region; it has helped to mobilize scientists in developing countries; it has established locally needed definitions of NCD variables; has served as a model for cohort studies in developing countries in nutrition transition with all socioeconomic constraints and has helped manpower education and development of local CVD risk scores for implementation of NCD management.
\end{abstract}

Keywords: Tehran Lipid and Glucose Study, Non-Communicable Disease, Iran

\section{Introduction}

The landmark Framingham Heart Study, planned in 1947 and its initial design paper was published in 1951 (1), was an important turning point in our evolving understanding of non-communicable diseases (NCD) in last century. Although the standardized measurement of risk factors of NCD and follow up in Framingham served as an important precedent for future cohort studies in developed countries (2), there have been a paucity of prospective investigation of the epidemiology of NCD in the developinglow income countries.

The legacy of Tehran Lipid and Glucose Study (TLGS) is that it was planned in a developing country in nutrition transition (3) for investigation of epidemiology of NCD and has continued follow up of 20 years (4). Special characteristics of TLGS could be summarized as follows:

1. Most NCD cohort studies have been performed on adult population. Framingham Heart Study recruited approximately 6000 adults, while TLGS consists if a cohort of 15000 family based individuals from 3 to 79 years of age (5).

2. Those cohort studies performed in a population of small city, such as Framingham may have operational ad- vantages, in particular in collection of outcome data. TLGS has population of approximately 8.5 million. Therefore, collection of outcome data from over 170 hospitals and moving of participants to different part of the city have made obstacles in management of the study.

3. The design of TLGS composed of collection of baseline data in 3 years and community lifestyle intervention for prevention of NCD in one third of study population, followed by re-collection of data every 3 years. Interventional studies carry special difficulties that observational studies do not have (6).

4. Executing a cohort study in developing country faces inadequacy in infrastructure of communication, social determinants, education, health structure and many related factors, which need special planning.

5. The success of recruiting $72.9 \%$ (Figure 1) of original cohort after nearly 2 decades has been mainly due to an expert team of social workers, with close connection to each family in the area of study.

6. The addition of Tehran Thyroid Study, Reproduction Study, Cardiometabolic Genetic Study in the population of TLGS had prepared ground for more extensive cross- 


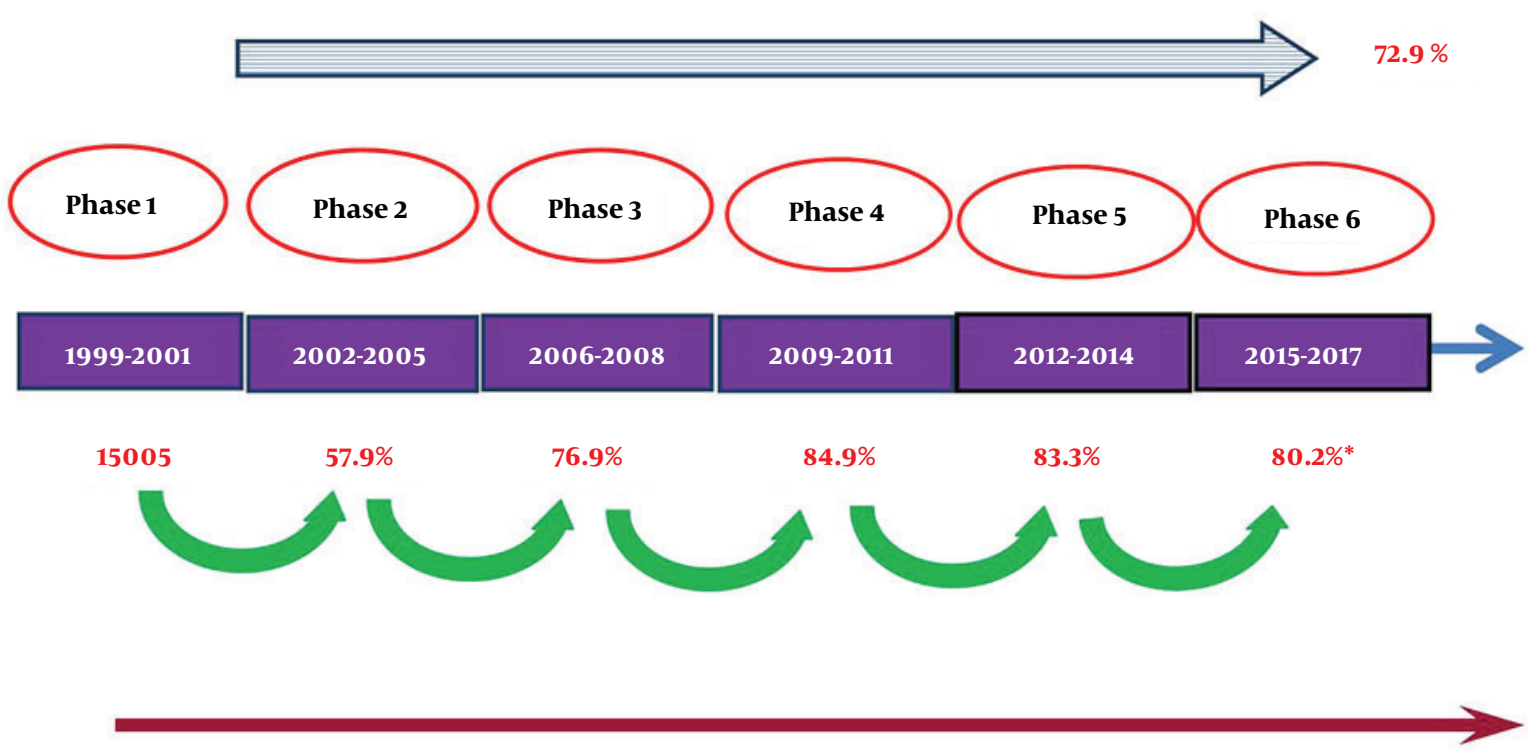

Continuous NCD Outcomes Follow-Up

Figure 1. Design of Tehran Lipid and Glucose Study. Each phase lasted 3 years. $72.9 \%$ of the original cohort have participated in phase 6 (18 years of follow up). ${ }^{*}$ Denotes percent of participation from previous phase.

specialty investigations, paving suitable path towards precision medicine.

Main outcome and implications of TLGS consist of factors of investigating risk in the development of NCD, effect of community lifestyle intervention, and findings from concomitant study in the thyroid, reproductive and genetic domain.

\section{Factors of Risk in the Development of NCD}

The concept of risk factors was first developed by Kannel et al. in 1961 describing the six-year follow up in the Framingham Heart Study (7). TLGS was the first to show the systemic and standardized follow up of NCD risk factors in a community in nutrition transition in a developing country (8). Figure 2 demonstrates steady increase in BMI, waist circumference, blood pressure, and percent of obesity in TLGS. Trends of NCD risk factors in the first 20 years of TLGS have been described in previous papers (9-24). Main findings have been included in Figures 2 and 3.

\subsection{Body Weight}

Prevalence of overweight and obesity which was 20.8 and $63.6 \%$ in 3 - 19 years age and adults respectively has increased in both young and adult population. The crude prevalence of obesity and abdominal obesity in adults has increased from 23.1 and $47.9 \%$ at baseline to 34.1 and $71.1 \%$ at the end of follow up, respectively. Relative risk of obesity was $1.62(1.49$ - 1.76) for men and 1.24 (1.19 - 1.29) for women. Relative risk for abdominal obesity was 1.46 (1.41 - 1.52) and $1.22(1.18$ - 1.27) in men and women, respectively (9).

In the TLGS, 2.0 and $7.7 \%$ of the adult population wee metabolically healthy obese (MHO) in total and obese population, respectively. Corresponding numbers for metabolically healthy but abdominal obese (MHAO) were 12.4 and $23.5 \%$ respectively. These two phenotypes were unstable conditions and nearly half of the individuals developed metabolic risks during follow-up. At follow up MHAO, but not MHO phenotype showed and increased risk of CVD compared to metabolically healthy non-abdominal obese individuals (25-27).

\subsection{Nutrition}

Consummation of whole grains, legumes, nuts and healthy dietary pattern reduced and consumption of white rice, salty/weet snacks increase risk of MetS. Higher adherence to healthy food choices were also associated with reduced odds of MetS, obesity, dyslipidemia and pattern. The western dietary pattern increased the association of polymorphism with MetS $(10,28-30)$.

Follow up studies showed that dietary pattern of twothird of participants was not in accordance with dietary recommendations. Higher dietary scores of variety and healthy dietary patterns were associated with reduced odds of dysglycemia (31-33). 

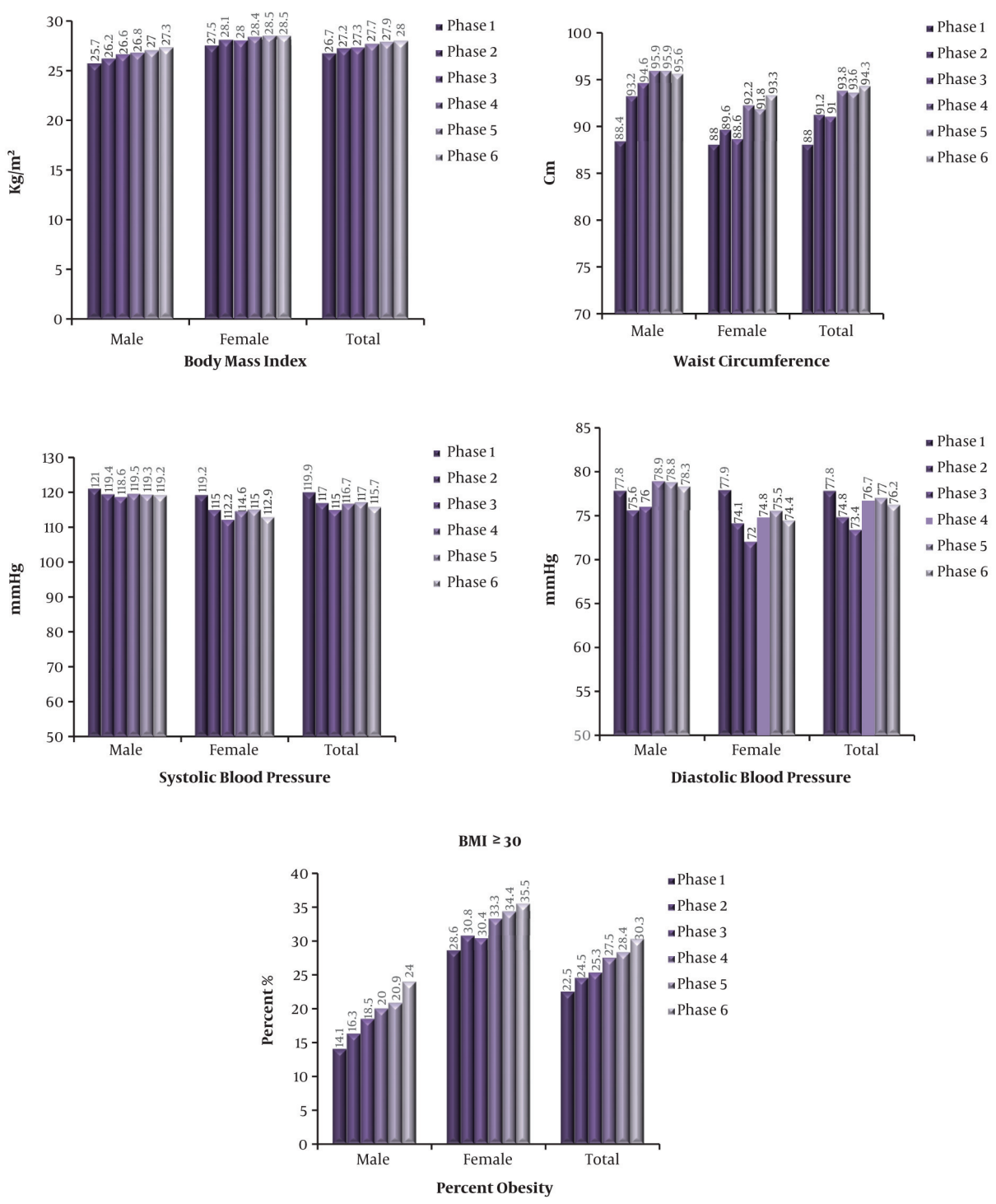

Figure 2. Mean body mass index (BMI), waist circumference (WC), systolic and diastolic blood pressure and percent obesity $\left(\mathrm{BMI} \geq 30 \mathrm{~kg} / \mathrm{m}^{2}\right)$ during 6 phases of the Tehran Lipid and Glucose Study. Each phase lasted 3 years. There have been increases in BMI, WC, diastolic BP and percent obesity during 18 years of follow up.

\subsection{Physical Activity}

At baseline, low physical activity was present in $69.8 \%$ with little change in the follow-up. The prevalence of physical inactivity increased with rise in BMI: $69.8 \%$ of overweight and $75.3 \%$ of obese men had low physical activity, with higher risk of metabolic syndrome, systolic blood pressure and elevated serum triglyceride (11-34).

\subsection{Blood Pressure}

The prevalence of hypertension was $23 \%$. Crude incidence rate was 33.6 per 1000 person-years. Age, baseline systolic BP and BMI, and baseline diastolic BP and waist circumference were important risk factors for isolated systolic and diastolic hypertension, respectively. Hypertension was associated with increased CVD, CVA and all cause mortality $(12,35,36)$.

\subsection{Tobacco Smoking}

The prevalence of tobacco smoking increased from 25.5 to $35.4 \%$ in men and from 3.4 to $6.8 \%$ in women during 10 years follow-up. Water- pipe use in youth also increased. Increased risk of combined IFG/IGT, hypertension and CVD in men and increase risk of chronic kidney disease in women 

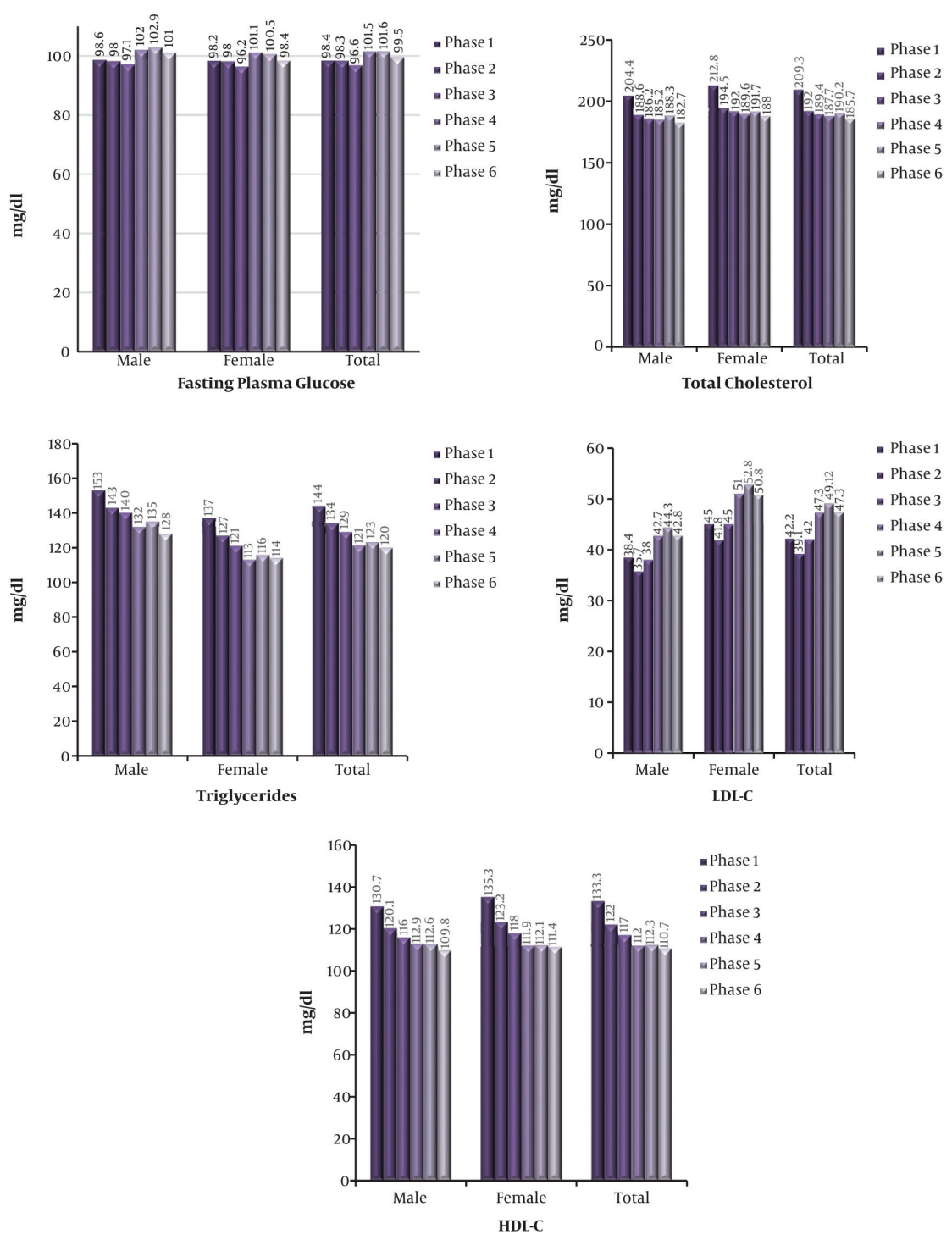

Figure 3. Mean serum concentrations of glucose and lipid profile during 6 phases of the Tehran Lipid and Glucose Study. Each phase lasted 3 years. There have been decreases in serum total cholesterol, triglycerides and LDL-C and increase in serum HDL-C, with no significant change in FPG.

smoker was shown (11), smoking contributed to $7.7 \%$ of all cause mortality with HR 1.75 (36).

\subsection{Serum Glucose}

At baseline the prevalence of diabetes was 13.2 and $14.7 \%$ in adult men and women, respectively. Incidence rate of diabetes in adults was 10 per 1000 person-year, and that of prediabetes was 36.3 per 1000 person-year. Diabetes was significantly associated with increased risk of CVD and death. Hyperinsulinemia, serum 25-OH vitamin D, alanin aminotraferase and waist circumference provided additional prognostic information beyond the traditional risk factors incident diabetes $(14,36,37)$.

\subsection{Serum Lipids}

The baseline prevalence of low HDL-C and high LDL-C among adolescents was 14 and $17 \%$, respectively (38). Corresponding figures for adults were 19 and $28 \%$, respectively (39). Serum total cholesterol and triglycerides were significantly higher in men than women and increase by advancing age in both genders. During over a decade follow up, significant decrease in serum concentrations of total cholesterol, triglycerides and LDL-C and increase in serum HDL-C occurred in both gender (40). Results 
were unchanged after excluding participants with prevalent CVD and those using lipid lowering medications: 1.5 and $3.7 \%$ at baseline and 9.0 and $11.4 \%$ after follow up in men and women, respectively. Therefore, some important part of correction of dyslipidemia was attributed to national program of changing solid oil to liquid oil production throughout the country in last decade of last century by the government (15).

\section{Related Findings to NCD}

\subsection{Metabolic Syndrome}

Based on ATP III definition, the prevalence was 30.1\% at baseline, $42 \%$ in women and $24 \%$ in men (41). The most prevalent metabolic abnormality was low-HDL. The incidence rate of metabolic syndrome was 551/10000 person/year. In adolescents the prevalence was $10.1 \%$. metabolic syndrome was a significant predictor of total and cardiovascular mortality in both gender (16-42).

\subsection{Chronic Kidney Disease}

The prevalence of CKD was 11.3 and $8.5 \%$ by 2 different definitions (43). The incident rates were 285 and 233 per 10000 person-years for women and men, respectively. Elevated waist circumference and waist gain were associated with increase incidence of CKD. In lean individuals, CKD was an indefindent predictor of CHD and stroke (17).

\subsection{Quality of Life}

Metabolic syndrome was associated with poor physical quality of life in women, particularly in those who had more components of metabolic syndrome. Only reproductive age women with metabolic syndrome were more likely to report poor physical component summary subset of short form health survey (18).

\subsection{Biochemical Findings}

In addition to FBS, GTT, serum lipids and lipoprotences, measurement of many biochemicals have been performed in TLGS. C-reactive protein, interluekine- 6 and homocysteine were found to be associated with NCDs. Levels of CRP and IL-6 was higher in subjects with abdominal obesity, as compared to normal weight individuals (19).

In Addition, circulating nitric oxide metabolites $\left(\mathrm{NO}_{\mathrm{x}}\right)$ was associated with the risk and could predict NCD. Findings suggested that $\mathrm{NO}_{3} / \mathrm{NO}_{2}$ exposure from usual diets may contribute to development of NCDs (20).

\subsection{Tehran Thyroid Study}

Thyroid study began in 5920 adults of TLGS and the design was published in 2013 (44). This study aimed to investigate the gap in knowledge regarding epidemiology of thyroid disorders and systematic evaluation of trend of thyroid hormones, TSH and thyroid antibodies in a population over time period. So far, it has defined the reference ranges of fT4, TSH and thyroid peroxidase antibody (TPOAb). The rate of persistent euthyroidism has been $93 \%$ and the incidence rate of thyroid disorders was estimated at 21 per 1000 person-year. Serum fT4 had negative association with insulin resistance in all and positive association with blood pressure only in men. No relation between various thyroid status and the prevalence and incidence of CVD was detected (21).

\subsection{Reproductive Studies}

A decrease in age of menarche from 14 to 13 years was observed during 6 decades. There was no specific trend in menopausal age. Findings showed good agreement between serum anti-mulerian hormone and predicted age of menopause (45). Prevalence of infertility was 17.3\%. Prevalence of PCOS and idiopathic hirsutism was 8.5 and 13.0\%, respectively. Significant association between PCOS with increased hazard of diabetes, prediabetes and risk of developing metabolic syndrome was observed only in women aged $\leq 40$ years $(22)$.

\subsection{Genetic Studies}

The association between variations in 26 genes were studied in 6 phenotypes and complex 17 trials. 47 variants were associated with NCDs and related traits (23). Extraindivuals and pedigrees have been collected during followup time and the data of genome wide studies are under analysis.

\subsection{Life Style Intervention}

A community-based intervention for life style modification was adapted following baseline data collection in TLGS. It was planned to educate trainers from the community, followed by supervision and evaluation from TLGS team. Educational interventions were performed by family-based, community based and school-based programs (6).

Baseline data of TLGS had shown higher prevalence of NCD risk factors compared to Western and Asia-Pacific countries. However, mild indirect interventions showed a decrease in the prevalence of metabolic syndrome and the incidence of diabetes and prediabetes. After 3.6 years of interventions, the incidence of diabetes was decreased by $65 \%(24,46,47)$. 
Table 1. Approximate Costs of Survey for Each Participant Per Year: Tehran Lipid and Glucose Study

\begin{tabular}{lcc}
\hline \multirow{2}{*}{ Item } & \multicolumn{2}{c}{ Expenditure } \\
\cline { 2 - 3 } & Rials & Euro $^{\mathbf{a}}$ \\
\hline History, physical exam and questionnaires & 60,000 & 1.2 \\
Elecrocardiogram & 40,000 & 0.8 \\
\hline Laboratory measurements & 70,000 & 1.4 \\
\hline Manegerial services and other costs & 830,000 & 16.6 \\
\hline Total & $1,000,000$ & 20.0 \\
\hline
\end{tabular}

${ }^{\text {a }}$ Exchange rate has varied during last 20 years, 5000 Rials per each Euro has been estimated as an average.

\section{TLGS as a Model for Other Cohort Studies}

Tehran Lipid and Glucose Study was the first prospective 20 year cohort study in West-Asia and Eastern Mediterranean region. Table 1 shows low survey cost of only 1,000,000 Rials (20 Euro) for each participant of TLGS per year of study. The success of TLGS, with over 500 peerreviewed Journal publications, motivated the establishment of many cohort studies in the region, in the past decade. In the Islamic Republic of Iran over 20 cohort studies have developed and a Concersium of Iranian Cohort has been formed. In 2018, approximately 150,000 people have entered Iranian cohort studies (48). These cohort studies will continue TLGS path to use standardized protocol for measurement of risk factors and outcomes of NCD's, to employ repeated examinations over time for detecting the progression of risk factors and to use multivariate analysis to disclose the independent contributions of multiple risk factors in NCDs.

\section{Contributions and Future Prospective}

Findings of TLGS, a 20 year long prospective study of NCDs in a developing country has produced many important lessons from this well controlled epidemiological investigation over the past 2 decades. The main lessons gained by TLGS have been (1) to mobilize scientists in countries other than developped ones to establish prospective cohort studies for assessment of risk factors of NCDs in their region, to correct many clinical misconceptions, to establish the impact of risk factors and the importance of multivariable risk factors influencing NCDs; (2) to establish locally needed definitions of variables; for example cut-offs of waist circumference for Iranians; (3) to show that with good management, complex cohort studies could be implemented in a rapidly growing country on nutrition transition; (4) to demonstrate that training the trainers in a community with minimal expenses could be effective in reducing incidence of diabetes, prediabets and metabolic syndrome; (5) to show that in situations with constraint budgets, with rising enthusiasm in dedicated researchers and personals, much sciences could be gained in health system research; (6) to announce unhealthy diet and poor physical activity of the community and to propose ways of change in lifestyle to the health authority; (7) to develop ways of exchange of knowledge in order to propagate findings to medical personnels and general population; to determine appropriate technological advances in molecular medicine and new interventional tools in population research in less developed countries. (8) to develop CVD risk scores based on data from local population and implement the formula in nationwide NCD management (IRA-PEN).

In recent years, the legacy of TLGS continues with genomic study including genom-wide study of TLGS participants, plans for metabolomic studies, more development of research in epigenetic domain and wider collaborations with scientists in different fields of medicine for employing more creativity and newer investigation tools. In addition, the close collaboration with various departments of the Ministry of Health and Medical Education makes this study unique to offer prevention methods for control of NCDs in countries in nutrition transition. For the future, all data gathered in TLGS could help the development of precision medicine in the region.

\section{Supplementary Material}

Supplementary material(s) is available here [To read supplementary materials, please refer to the journal website and open PDF/HTML].

\section{Acknowledgments}

The authors thank the participants in the TLGS, the staff of TLGS unit in east Tehran city and the staff of the Research Institute of Endocrine Sciences, Shahid Beheshti University of Medical Sciences, for their science contributions in advancing knowledge and prevention of NCDs. We are indebted to many investigators who have contributed in design, consultation and have published over 900 English and Persian papers of TLGS (See Supplementary File).

\section{References}

1. Dawber TR, Meadors GF, Moore FE, Jr. Epidemiological approaches to heart disease: The Framingham study. Am J Public Health Nations Health. 1951;41(3):279-81. [PubMed: 14819398]. [PubMed Central: PMC1525365]. 
2. Wong ND, Levy D. Legacy of the Framingham Heart Study: Rationale, design, initial findings, and implications. Glob Heart. 2013;8(1):3-9. doi: 10.1016/j.gheart.2012.12.001. [PubMed: 25690260].

3. Ghassemi H, Harrison G, Mohammad K. An accelerated nutrition transition in Iran. Public Health Nutr. 2002;5(1A):149-55. doi: 10.1079/PHN2001287. [PubMed:12027278].

4. Azizi F. Tehran Lipid and Glucose Study: A legacy for prospective community-based research. Arch Iran Med. 2014;17(6):392-3. [PubMed: 24916522].

5. Azizi F, Rahmani M, Madjid M, Emami H, Mirmiran P, Hadjipour R. [Tehran Lipid and Glucose Study (TLGS): Rationale and design]. Int J Endocrinol Metab. 2000;2(2):77-86. Persian.

6. Azizi F, Ghanbarian A, Momenan AA, Hadaegh F, Mirmiran P, Hedayati $M$, et al. Prevention of non-communicable disease in a population in nutrition transition: Tehran Lipid and Glucose Study phase II. Trials. 2009;10:5. doi: 10.1186/1745-6215-10-5. [PubMed: 19166627]. [PubMed Central: PMC2656492].

7. Kannel WB, Dawber TR, Kagan A, Revotskie N, Stokes J. Factors of risk in the development of coronary heart disease-six year follow-up experience. The Framingham study. Ann Intern Med.1961;55:33-50. [PubMed: 13751193].

8. Azizi F, Rahmani M, Emami H, Mirmiran P, Hajipour R, Madjid M, et al. Cardiovascular risk factors in an Iranian urban population: Tehran Lipid and Glucose Study (phase 1). Soz Praventivmed. 2002;47(6):408 26. [PubMed: 12643001].

9. Barzin M, Valizadeh M, Serahati S, Mahdavi M, Azizi F, Hosseinpanah F. Overweight and obesity: Findings from 20 years of the Tehran Lipid and Glucose Study. Int J Endocrinol Metab. 2018;16(Suppl). doi: 10.5812/ijem.84778.

10. Hosseini-Esfahani F, Hosseinipour S, Asghari G, Bahadoran Z, Moslehi $\mathrm{N}$, Golzarand M, et al. Nutrition and cardio-metabolic risk factors: Findings from 20 years of the Tehran Lipid and Glucose Study. Int J Endocrinol Metab. 2018;16(Suppl). doi: 10.5812/ijem.84772.

11. Sheikholeslami S, Ghanbarian A, Azizi F. The impact of physical activity on non-communicable diseases: Findings from 20 years of the Tehran Lipid and Glucose Study. Iran J Endocrinol Metab. 2018;16(Suppl). doi: 10.5812/ijem.84740.

12. Abdi H, Amouzegar A, Tohidi M, Azizi F, Hadaegh F. Blood pressure and hypertension: Findings from 20 years of the Tehran Lipid and Glucose Study (TLGS). Iran J Endocrinol Metab. 2018;16(Suppl). doi: 10.5812/ijem.84769.

13. Parizadeh D, Momenan AB, Amouzegar A. Tobacco smoking: 20 years of Tehran Lipid and Glucose Study. Int J Endocrinol Metab. 2018. doi: 10.5812/ijem.84738.

14. Ramezankhani A, Harati H, Bozorgmanesh M, Tohidi M, Khalili D, Azizi F, et al. Diabetes mellitus: Findings from 20 years of the Tehran Lipid and Glucose Study. Int J Endocrinol Metab. 2018;16(Suppl). doi: 10.5812/ijem.84784.

15. Baghbani-Oskouei A, Tohidi M, Asgari S, Ramezankhani A, Azizi F, Hadaegh F. Serum Lipids during 20 years in the Tehran Lipid and Glucose Study: Prevalence, trends and impact on non-communicable diseases. Int J Endocrinol Metab. 2018;16(Suppl). doi: 10.5812/ijem.84750.

16. Hosseini-Esfahani F, Bahadoran Z, Moslehi N, Asghari G, Yuzbashian E, Hosseinpour-Niazi S, et al. Metabolic syndrome: Findings from 20 years of the Tehran Lipid and Glucose Study. Int J Endocrinol Metab. 2018;16(Suppl). doi: 10.5812/ijem.84771.

17. Eftekharzadeh A, Hosseinpanah F, Valizadeh M, Barzin M, Mahdavi M, Azizi F. Legacy of the Tehran Lipid and Glucose Study: Chronic kidney disease. Int J Endocrinol Metab. 2018;16(Suppl). doi: 10.5812/ijem.84761.

18. Amiri P, Jalali-Farahani S, Vahedi-Notash G, Cheraghi L, Azizi F. Healthrelated quality of life in Tehran Lipid and Glucose Study. Int J Endocrinol Metab. 2018;16(Suppl). doi: 10.5812/ijem.84745.

19. Hedayati M, Daneshpour MS, Zarkesh M, Zarif Yeganeh M, Sheikholeslami S, Faam B, et al. Biochemical assessment: Findings from 20 years of the Tehran Lipid and Glucose Study. Int J Endocrinol Metab. 2018;16(Suppl). doi: 10.5812/ijem.84783.
20. Bahadoran Z, Mirmiran P, Jeddi S, Momenan AA, Azizi F, Ghasemi A. The nitrate-nitrite-nitric oxide pathway: Findings from 20 years of the Tehran Lipid and Glucose Study. Int J Endocrinol Metab. 2018;16(Suppl). doi: $10.5812 /$ ijem.84775.

21. Amouzegar A, Mehran L, Takyar M, Abdi H, Azizi F. Tehran Thyroid Study (TTS). Int J Endocrinol Metab. 2018;16(Suppl). doi: 10.5812/ijem.84727.

22. Ramezani F, Behboudi-Gandevani S, Rostami Dovom M, Farahmand M, Minooee S, Noroozzadeh M, et al. Reproductive assessment: Findings from 20 years of the Tehran Lipid and Glucose Study. Int J Endocrinol Metab. 2018;16(Suppl). doi:10.5812/ijem.84786.

23. Daneshpour MS, Hedayati M, Sedaghati-Khayat B, Guity K, Zarkesh M, Akbarzadeh $\mathrm{M}$, et al. Genetic identification for non-communicable disease: Findings from 20 years of the Tehran Lipid and Glucose Study. Int J Endocrinol Metab. 2018;16(Suppl). doi: 10.5812/ijem.84744.

24. Khalili D, Azizi F, Asgari S, Zadeh-Vakili A, Momenan AA, Ghanbarian A, et al. Outcomes of a longitudinal population-based Cohort Study and pragmatic community trial: Findings from 20 years of the Tehran Lipid and Glucose Study. Int J Endocrinol Metab. 2018;16(Suppl). doi: 10.5812/ijem.84748.

25. Hosseinpanah F, Nazeri P, Ghareh S, Tohidi M, Azizi F. Predictors of the incident metabolic syndrome in healthy obese subjects: A decade of follow-up from the Tehran Lipid and Glucose Study. Eur J Clin Nutr. 2014;68(3):295-9. doi: 10.1038/ejcn.2013.142. [PubMed: 23963276].

26. Keihani S, Hosseinpanah F, Barzin M, Serahati S, Doustmohamadian S, Azizi F. Abdominal obesity phenotypes and risk of cardiovascular disease in a decade of follow-up: The Tehran Lipid and Glucose Study. Atherosclerosis. 2015;238(2):256-63. doi: 10.1016/j.atherosclerosis.2014.12.008. [PubMed: 25540856].

27. Mirzaei B, Abdi H, Serahati S, Barzin M, Niroomand M, Azizi F, et al. Cardiovascular risk in different obesity phenotypes over a decade followup: Tehran Lipid and Glucose Study. Atherosclerosis. 2017;258:65-71. doi: 10.1016/j.atherosclerosis.2017.02.002. [PubMed: 28213199].

28. Mirmiran P, Hekmatdoost A, Azizi F. Metabolic syndrome is associated with adherence to an unhealthy diet. Diabetes Care. 2007;30(9). e93. doi: 10.2337/dc06-1928. [PubMed: 17726183].

29. Hosseini-Esfahani F, Jessri M, Mirmiran P, Sadeghi M, Azizi F. Does the diet of Tehranian adults ensure compliance with nutritional targets? Observations from the Tehran Lipid and Glucose Study. Public Health Nutr. 2011;14(9):1539-48. doi: 10.1017/S1368980011000711. [PubMed: 21557877].

30. Asghari G, Yuzbashian E, Mirmiran P, Hooshmand F, Najafi R, Azizi F. Dietary approaches to stop hypertension (DASH) dietary pattern is associated with reduced incidence of metabolic syndrome in children and adolescents. J Pediatr. 2016;174:178-184 e1. doi: 10.1016/j.jpeds.2016.03.077. [PubMed: 27156186].

31. Mirmiran P, Hosseini-Esfahanil F, Jessri M, Mahan LK, Shiva N, Azizis F. Does dietary intake by Tehranian adults align with the 2005 dietary guidelines for Americans? Observations from the Tehran Lipid and Glucose Study.J Health Popul Nutr.2011;29(1):39-52. [PubMed: 21528789]. [PubMed Central: PMC3075058].

32. Bahadoran Z, Mirmiran P, Momenan AA, Azizi F. Allium vegetable intakes and the incidence of cardiovascular disease, hypertension, chronic kidney disease, and type 2 diabetes in adults: A longitudinal follow-up study. J Hypertens. 2017;35(9):1909-16. doi: 10.1097/HJH.0000000000001356. [PubMed: 28319598].

33. Asghari G, Ghorbani Z, Mirmiran P, Azizi F. Nut consumption is associated with lower incidence of type 2 diabetes: The Tehran Lipid and Glucose Study. Diabetes Metab. 2017;43(1):18-24. doi: 10.1016/j.diabet.2016.09.008. [PubMed: 27865656].

34. Fam B, Amouzegar A, Arzhan S, Ghanbariyan A, Delshad M, Hosseinpanah $\mathrm{F}$, et al. Association between physical activity and metabolic risk factors in adolescents: Tehran Lipid and Glucose Study. Int I Prev Med. 2013;4(9):1011-7. [PubMed: 24130941]. [PubMed Central: PMC3793481]. 
35. Sardarinia M, Akbarpour S, Lotfaliany M, Bagherzadeh-Khiabani F, Bozorgmanesh M, Sheikholeslami F, et al. Risk factors for incidence of cardiovascular diseases and all-cause mortality in a Middle Eastern population over a decade follow-up: Tehran Lipid and Glucose Study. PLoS One. 2016;11(12). e0167623. doi: 10.1371/journal.pone.0167623. [PubMed: 27930696]. [PubMed Central: PMC5145170].

36. Parizadeh D, Ghahvehchian H, Asgari S, Momenan AA, Azizi F, Hadaegh F. The association between changes in blood pressure components and incident cardiovascular diseases. Blood Press. 2017;26(6):341-9. doi: 10.1080/08037051.2017.1353882. [PubMed: 28708028].

37. Ramezankhani A, Pournik O, Shahrabi J, Azizi F, Hadaegh F. An application of association rule mining to extract risk pattern for type 2 diabetes using Tehran Lipid and Glucose Study database. Int J Endocrinol Metab. 2015;13(2). e25389. doi: 10.5812/ijem.25389. [PubMed: 25926855]. [PubMed Central: PMC4393501].

38. Azizi F, Rahmani M, Madjid M, Allahverdian S, Ghanbili J, Ghanbarian A, et al. Serum Lipid levels in an Iranian population of children and adolescents: Tehran Lipid and Glucose Study. Europ J Epidemiol. 2001;17(3):281-8. doi: 10.1023/a:1017932212350.

39. Azizi F, Rahmani M, Ghanbarian A, Emami H, Salehi P, Mirmiran $P$, et al. Serum lipid levels in an Iranian adults population: Tehran Lipid and Glucose Study. Europ J Epidemiol. 2002;18(4):311-9. doi: 10.1023/a:1023606524944.

40. Kheirandish M, Asgari S, Lotfaliany M, Bozorgmanesh M, Saadat N, Tohidi M, et al. Secular trends in serum lipid levels of a Middle Eastern adult population; 10 years follow up in Tehran Lipid and Glucose Study. Lipids Health Dis. 2014;13:20. doi: 10.1186/1476-511X-13-20. [PubMed: 24456699]. [PubMed Central: PMC3912503].

41. Azizi F, Salehi P, Etemadi A, Zahedi-Asl S. Prevalence of metabolic syndrome in an urban population: Tehran Lipid and Glucose Study. Diabetes Res Clin Pr. 2003;61(1):29-37. doi: 10.1016/s0168-8227(03)00066-4.
42. Amouzegar A, Mehran L, Hasheminia M, Kheirkhah Rahimabad P, Azizi $F$. The predictive value of metabolic syndrome for cardiovascular and all-cause mortality: Tehran Lipid and Glucose Study. Diabetes Metab Res Rev. 2017;33(1). doi: 10.1002/dmrr.2819. [PubMed: 27155315].

43. Hosseinpanah F, Kasraei F, Nassiri AA, Azizi F. High prevalence of chronic kidney disease in Iran: A large population-based study. BMC Public Health. 2009;9:44. doi: 10.1186/1471-2458-9-44. [PubMed: 19183493]. [PubMed Central: PMC2658666].

44. Azizi F, Amouzegar A, Delshad H, Tohidi M, Mehran L, Mehrabi Y Natural course of thyroid disease profile in a population in nutrition transition: Tehran Thyroid study. Arch Iran Med. 2013;16(7):418-23. [PubMed: 23808780].

45. Tehrani FR, Solaymani-Dodaran M, Tohidi M, Gohari MR, Azizi F. Modeling age at menopause using serum concentration of antimullerian hormone. J Clin Endocrinol Metab. 2013;98(2):729-35. doi: 10.1210/jc.2012-3176. [PubMed: 23316087].

46. Azizi F, Mirmiran P, Momenan AA, Hadaegh F, Habibi Moeini A Hosseini $F$, et al. The effect of community-based education for lifestyle intervention on the prevalence of metabolic syndrome and its components: Tehran Lipid and Glucose Study. Int J Endocrinol Metab. 2013;11(3):145-53. doi: 10.5812/ijem.5443. [PubMed: 24348586]. [PubMed Central: PMC3860109].

47. Harati H, Hadaegh F, Momenan AA, Ghanei L, Bozorgmanesh MR, Ghanbarian A, et al. Reduction in incidence of type 2 diabetes by lifestyle intervention in a Middle Eastern community. Am J Prev Med. 2010;38(6):628-636 e1. doi: 10.1016/j.amepre.2010.03.003. [PubMed: 20494239].

48. Fahimfar N, Khalili D, Sepanlou SG, Malekzadeh R, Azizi F, Mansournia MA, et al. Cardiovascular mortality in a Western Asian country: Results from the Iran Cohort Consortium. BMJ Open. 2018;8(7). e020303. doi: 10.1136/bmjopen-2017-020303. [PubMed: 29980541]. [PubMed Central: PMC6042599]. 